\title{
Dimensionamento amostral para a caracterização da qualidade póscolheita do maracujá-amarelo ${ }^{1}$
}

\author{
Antonione Araujo Coelho ${ }^{2}$ Eliana Monteiro Soares de Oliveira ${ }^{2}$, Eder Dutra de Resende ${ }^{3}$, \\ José Tarcisio Lima Thiébaut ${ }^{4}$
}

\section{RESUMO}

Este trabalho teve, como objetivo, determinar o tamanho mínimo de amostras representativas de uma população infinita de frutos, para caracterizar a qualidade pós-colheita do maracujá-amarelo, decorrente do tamanho do fruto e do estádio de maturação. Foram coletadas amostras padronizadas de 20 frutos, em lavoura comercial, em Campos dos Goytacazes (RJ), e os dados foram interpretados, considerando-se o método de amostragem simples ao acaso. Avaliaram-se a coloração e a espessura da casca, a razão comprimento/largura, o rendimento em suco, a massa do fruto, a acidez, o pH e os conteúdos de vitamina $\mathrm{C}$, sólidos solúveis totais, açúcares redutores e não redutores e açúcares solúveis totais. A amostragem padronizada de 20 frutos foi representativa de uma população infinita, quando utilizada para análises químicas de maracujás maduros, colhidos com mais de 30\% de coloração amarela da casca. Medidas de rendimento em suco e espessura de casca exigiram tamanhos de amostras maiores.

Palavras-chave: Passiflora edulis f. flavicarpa Deg., amostragem, tamanho do fruto, estádio de maturação, caracterização química.

\section{ABSTRACT}

\section{Sample size for postharvest quality characterization of yellow passion fruits}

The objective of this study was to determine the minimum sample size of an infinite fruit population to evaluate postharvest quality of yellow passion fruit as a function of fruit size and ripening stage. Standardized samples were collected from 20 fruits from a commercial orchard in Campos dos Goytacazes (RJ) and the data were interpreted using the simple random sampling method. The evaluated traits were peel color, peel thickness, juice yield, fruit mass, content of total soluble solids, $\mathrm{C}$ vitamin, $\mathrm{pH}$, titratable acidity, reducers and non-reducers and total soluble sugars. The standardized sampling of 20 fruits was representative of an infinite population when used for chemical analysis of ripe yellow passion fruits harvested with more than $30 \%$ of yellow peel. Measures of juice yield and peel thickness required larger sample sizes.

Key words: Passiflora edulis f. flavicarpa Deg., sampling, fruit size, ripening stage, chemical characterization.

\footnotetext{
Recebido para publicação em novembro de 2008 e aprovado em janeiro de 2011

Extraído da Dissertação de Mestrado em Produção Vegetal por Antonione Araújo Coelho, Centro de Ciências e Tecnologias Agropecuárias da UENF.

2 Engenheiro-Agrônomo, Mestre. Laboratório de Tecnologia de Alimentos, CCTA/UENF, Avenida Alberto Lamego, 2000, Parque Califórnia, 28013-602, Campos dos Goytacazes R.J., aacoellho@yahoo.com.br

Engenheiro de Alimentos, Doutor. Laboratório de Tecnologia de Alimentos, CCTA/UENF, eresende@uenf.br (autor para correspondência)

${ }^{4}$ Engenheiro-Agrônomo, Doutor. Laboratório de Engenharia Agrícola, CCTA/UENF, jtt1512@uenf.br
} 


\section{INTRODUÇÃO}

O maracujazeiro pertence à família passifloracea, da ordem passiflorales. Esta família compreende 18 gêneros e cerca de 630 espécies, distribuídas, principalmente, nas regiões tropicais da América, Ásia e África. A maioria das espécies de maracujá é considerada perene, existindo, porém, um pequeno número de espécies anuais (Vanderplanck, 1996 citado por Miranda 2004, Cunha et al., 2002).

Os maiores produtores mundiais localizam-se na América do Sul, onde o Brasil, Colômbia, Peru e Equador são os maiores exportadores. O Brasil é o maior produtor mundial de maracujá-amarelo, mas alguns países africanos também contribuem com uma pequena exportação de frutas frescas para o continente europeu. Segundo dados do IBGE (2008), a produção brasileira, em 2006, atingiu 615.196 toneladas de frutos, em uma área plantada de 44.363 hectares, com rendimento médio de $13.867 \mathrm{~kg} / \mathrm{ha}$. Os estados maiores produtores são Bahia, Espírito Santo, São Paulo, Minas Gerais, Sergipe e Rio de Janeiro.

O maracujá-amarelo tem despertado grande interesse de fruticultores, face a sua rápida produção em relação a outras frutíferas e a sua grande aceitação no mercado. Ele é usado para consumo "in natura" e para a industrialização. Sua importância econômica reside no suco integral a $14{ }^{\circ} \mathrm{Brix}$, no néctar e no suco concentrado a $50^{\circ} \mathrm{Brix}$. O suco é muito consumido, por possuir valor nutritivo e por ter sabor e aroma exóticos e característicos, além da acidez acentuada (Sândi, 2003).

Nas pesquisas de avaliação da qualidade pós-colheita dos frutos, assim como em outras pesquisas experimentais, espera-se que a maior fração da variabilidade ocorrida entre as parcelas seja atribuída ao efeito dos tratamentos aplicados. Porém, por mais cuidados que se tenha na condução dos experimentos, ocorrem variações devidas ao erro experimental (Steel et al., 1997). Diversas fontes de erro experimental podem ser destacadas: a heterogeneidade do material experimental utilizado, tipo de tratamento, aplicação irregular de tratos culturais, ataques de pragas e doenças, injúrias causadas por sucessivas colheitas na mesma planta e a heterogeneidade de solo (Ramalho et al., 2000).

De acordo com a variável estudada e com a quantidade de subunidades dentro da unidade experimental, torna-se necessário fazer uma amostragem. Contudo, caso ela não seja homogênea e representativa, ocorre um aumento no erro experimental, pois um determinado tratamento ora é favorecido, ora é prejudicado por erros de sub ou superamostragem (Storck \& Lopes, 1997). A determinação do tamanho da amostra é importante em qualquer experimento científico, ou em trabalhos práticos de controle de qualidade, pois, se esse tamanho for menor do que o necessário, serão obtidas estimativas pouco precisas, podendo até invalidar o trabalho. Entretanto, se forem tomadas amostras excessivas, serão despendidos tempo e recursos desnecessários.

Com o objetivo de reduzir o número de plantas por parcela para a variável altura da planta do algodoeiro, Freitas et al.(2001) verificaram que, à medida que se aumentava o número de plantas, o Teste $\mathrm{F}$ passou a ser mais eficiente para verificar a significância do efeito de tratamento, recomendando-se, ao final, seis plantas por parcela como tamanho mínimo de amostra.

$\mathrm{Na}$ avaliação do tamanho amostral para estimar o teor de sólidos solúveis totais em talhões de melão amarelo, Nunes et al.(2006) identificaram a estabilização das estimativas da variância das medidas a partir de amostragens de 15 frutos. Em amostragens maiores, o aumento do número de frutos nas subamostras não provocava mudanças significativas nas estimativas do conteúdo de sólidos solúveis totais.

O objetivo deste trabalho foi determinar o tamanho mínimo de amostras representativas de uma população infinita dos frutos, para se ter estimativas confiáveis na caracterização física e química da qualidade pós-colheita do maracujá-amarelo (Passiflora edulis f. flavicarpa Degener).

\section{MATERIAL E MÉTODOS}

Neste trabalho, foram utilizados frutos de maracujáamarelo (Passiflora edulis f. flavicarpa Degener), colhidos em campo comercial, localizado no município de Campos dos Goytacazes-RJ, região norte fluminense. Utilizouse um sistema de polinização manual, em uma área plantada de 1,38 ha, com declividade de 0 a $5 \%$ e solo do tipo areno argiloso. O sistema de condução das plantas foi do tipo espaldeira, com um fio, com distâncias, entre linhas, de 3,5 metros e, entre plantas, de 4 metros, e densidade populacional de 833 plantas/ha. O sistema de irrigação foi do tipo gotejamento, com intervalo de oito dias entre irrigações. A colheita dos frutos ocorreu entre maio e agosto. Este período é caracterizado por precipitação média mensal de $53 \pm 10 \mathrm{~mm}$ de chuva, temperatura média mensal de $21 \pm 1,5^{\circ} \mathrm{C}$ e umidade relativa média mensal de $80 \pm 5$ $\%$ UR. Os frutos foram colhidos de maneira padronizada, com cinco lotes de tamanhos decrescentes e sete estádios de maturação.

Para a caracterização física dos frutos de acordo com o tamanho, os maracujás foram selecionados em cinco lotes de tamanhos homogêneos, utilizando-se um paquímetro manual para a realização das medições de comprimento longitudinal e largura equatorial dos frutos. Neste experimento, foram padronizados o estádio de maturação (frutos totalmente maduros) e o formato oval, mantendo- 
se a homogeneidade das amostras para cada tamanho, levando-se em consideração o bom aspecto fitossanitário.

Para a caracterização física e química, em função do estádio de maturação,foram colhidos sete lotes de maracujás com 40 frutos cada, padronizando-se, subjetivamente, de maneira decrescente, os sete estádios de maturação entre os estádios totalmente verde e completamente amarelo. Em seguida, os frutos foram lavados e sanitizados com água clorada (100 ppm de cloro ativo) e secos. Metade do lote de frutos de cada estádio de maturação foi caracterizada por análises físicas e químicas no dia da colheita. A outra metade foi estocada, a $22{ }^{\circ} \mathrm{C}$ e $90 \%$ UR, até o completo amarelecimento da casca.

A coloração da casca foi medida, usando-se o Colorímetro Hunterlab MiniScan Spectrophotometer (MiniScan XE Plus), sendo realizada em dois pontos equidistantes da face exposta e não exposta do fruto, compreendendo a região mediana da parte superior (pedúnculo) e inferior (base) dos frutos. Medidas do parâmetro de Hunter $b$ foram utilizadas para definir a escala de maturação dos frutos, conforme descrito por Vianna-Silva et al.(2008). Para as medidas de rendimento em suco, foi feita a extração e pesagem da polpa bruta em balança analítica (Gehaka, AG 2000) e o material foi processado em um homogeneizador (marca britânia), no módulo pulsar, em seguida filtrado em tela de filó com malha de 1,0 mm previamente pesada. Com o auxílio de um espremedor manual, foi feita a separação do suco e do resíduo da polpa, composta por arilo e sementes do fruto. O peso do resíduo com o filó foi avaliado em balança analítica, sendo discriminado no cálculo do rendimento de suco. Tal procedimento, foi adotado para minimizar erros em função do material que possa ter ficado retido nos utensílios de extração. O percentual de casca foi obtido pela diferença entre o peso total do fruto e o peso da polpa bruta, padronizado para 100 gramas.

A acidez titulável foi determinada, utilizando-se cerca de $2 \mathrm{~g}$ da amostra diluída em água destilada, até o volume de $25 \mathrm{ml}$, e tituladas com $\mathrm{NaOH} 0,1 \mathrm{~N}$, conforme a metodologia descrita pela A.O.A.C. (1970). A determinação de ácido ascórbico (AA) foi feita pelo método da A.O.A.C., baseado na reação de oxirredução, cujo agente oxidante foi o 2,6 Dicloroindofenol e uma solução de ácido oxálico como estabilizante. As medidas de sólidos solúveis totais (SST) foram feitas, utilizando duas gotas do suco, por meio de medidas diretas em refratômetro digital marca ATAGO modelo PR-201, com correção automática dos valores, de acordo com a temperatura, sendo os resultados expressos em ${ }^{\circ}$ Brix. A determinação dos açúcares redutores (AR) foi feita pelo método Eynon Lane (Lane \& Eynon, 1934). Os resultados obtidos foram expressos em gramas de AR por $100 \mathrm{~mL}$ de suco. Para determinação dos açúcares solúveis totais (AST), procedeu-se à hidrólise em meio ácido, conforme o método de Eynon
Lane. O conteúdo de açúcares não redutores (ANR) foi obtido por diferença entre os açúcares solúveis totais e os açúcares redutores.

Os dados foram avaliados segundo o método da amostragem simples ao acaso, considerando-se uma população infinita de frutos. O tamanho mínimo de amostras foi calculado com base na análise de variância das medidas de 20 amostras de maracujás, previamente padronizadas quanto ao tamanho e estádio de maturação dos frutos, considerando-se uma probabilidade de ocorrência em $95 \%$ da população e um desvio de $10 \%$ das medidas em torno da média de cada atributo de qualidade.

$n=\left(\mathrm{t}^{2}\right.$ 米 $\left.\mathrm{v}^{2}\right) / \mathrm{d}^{2}$

em que

$n$ : Tamanho mínimo da amostra;

t: Valor tabelado no nível 0,05 de significância com (n1) graus de liberdade;

v: Coeficiente de variação das medidas (\%);

d: Desvio de $10 \%$ em torno da média amostral de população infinita.

As análises foram realizadas com aporte do programa Sistema para Análises Estatísticas e Genéticas, versão 9.1, desenvolvido pela Universidade Federal de Viçosa (SAEG, 2007).

\section{RESULTADOS E DISCUSSÃO}

Os cinco padrões de tamanhos, utilizados neste trabalho, estão indicados na Tabela 1 e contemplam quatro classes descritas por Nascimento et al.(1999), em que os frutos de padrões um e dois são classificados como Extra 3A, o padrão três é Extra A, o padrão quatro é Extra e o padrão cinco é Especial.

O dimensionamento amostral para as medidas de rendimento em suco (RS), espessura de casca (EC), razão comprimento/largura (RAZÃO C/L) e peso dos frutos em função do tamanho dos maracujás, está indicado na Tabela 2. Verifica-se que as amostras constituídas de 20 frutos foram representativas de uma população infinita de maracujás, a $5 \%$ de significância e a um desvio de $10 \%$ em torno da média amostral. Entretanto, na avaliação da influência do tamanho do fruto sob a espessura de casca necessita-se de amostras entre 35 e 58 frutos, na maioria dos padrões de tamanho. Isto foi devido ao grande coeficiente de variação dessas medidas.

Os sete estádios de maturação padronizados, subjetivamente, no campo foram caracterizados pela fração de cor amarela na casca, definida pelo parâmetro de Hunter $b$, conforme a seguinte escala de maturação: estádio (1) com $0 \%$ de área da casca amarelada, estádio (2) com 5,1\% de área amarelada, estádio (3) com 30,7\% de área amarela- 
da, estádio (4) com 40,3\% de área amarelada, estádio (5) com $66,1 \%$ de área amarelada, estádio (6) com 74,7\% de área amarelada e estádio (7) com 98,4\% de área da casca amarelada.

As amostras de 20 frutos, nos diversos estádios de maturação, foram representativas de uma população infinita, quando utilizadas para a caracterização física dos maracujás, no momento da colheita e após a estocagem, conforme observado nas Tabelas 3 e 4, respectivamente. Contudo, na caracterização da cor da casca pelo parâmetro de Hunter $a$, no momento da colheita, necessitou-se de amostras de até 43 frutos nos estádios finais de maturação, quando se analisou a face exposta do fruto. $\mathrm{O}$ tamanho da amostra atingiu 136 frutos, quando se analisou a face não exposta. $\mathrm{O}$ alto coeficiente de variação das medidas de Hunter $a$ é atribuído à grande variabilidade deste parâmetro, indicando a degradação irregular da cor verde da casca, notadamente na face não exposta. Valores altos de coeficiente de variação de Hunter $a$ foram também observados nos frutos maduros, após o armazenamento, necessitando de amostras de até 56 frutos (Tabela 4).

$\mathrm{Na}$ avaliação da espessura de casca, de acordo com o estádio de maturação, verificou-se que o tamanho de amostras mínimo pode atingir até 87 frutos, para avaliações no momento da colheita (Tabela 3), e 48 frutos, para avaliações após a estocagem (Tabela 4), com maior coeficiente de variação nos frutos provenientes dos dois primeiros estádios, que estavam em ponto de colheita imaturo. Esse efeito de imaturidade nos dois primeiros estádios influenciou também as medidas de rendimento em suco, que necessitaram de amostras de 32 frutos, no momento da colheita (Tabela 3), e de 43 frutos, após o armazenamento (Tabela 4).

Na caracterização química do suco, as amostras de 20 frutos foram representativas de uma população infinita de maracujás, para as medidas de vitamina $\mathrm{C}$, acidez, $\mathrm{pH}$,

Tabela 1. Medidas físicas dos frutos de maracujá-amarelo, colhidos em cinco lotes de padrões decrescentes de tamanhos

\begin{tabular}{lccc}
\hline Padrões de tamanhos & Massa $^{*}(\mathbf{g})$ & Comprimento* $^{*}(\mathbf{c m})$ & Largura $^{*}(\mathbf{c m})$ \\
\hline 1 & $251,5( \pm 32,0)$ & $11,0( \pm 0,5)$ & $8,6( \pm 0,4)$ \\
2 & $237,4( \pm 32,3)$ & $10,9( \pm 0,8)$ & $8,2( \pm 0,4)$ \\
3 & $144,6( \pm 24,7)$ & $9,7( \pm 0,5)$ & $7,3( \pm 0,3)$ \\
4 & $123,3( \pm 12,6)$ & $9,0( \pm 0,4)$ & $6,6( \pm 0,4)$ \\
5 & $77,5( \pm 12,3)$ & $7,0( \pm 0,4)$ & $5,9( \pm 0,3)$ \\
\hline
\end{tabular}

* valores entre parênteses representam o erro padrão das medidas

Tabela 2. Tamanho mínimo de amostras representativo de uma população infinita de maracujá-amarelo para as medidas de rendimento em suco (RS), espessura de casca (EC), razão comprimento/largura (Razão C/L) e massa dos frutos, considerando 5\% de probabilidade e desvio de $10 \%$ em torno da média

Tamanho mínimo de amostras (no frutos)

\begin{tabular}{|c|c|c|c|c|}
\hline Padrões de Tamanho & $\mathbf{R S}^{*}(\%)$ & $\mathbf{E C} C^{*}(\mathbf{m m})$ & RAZÃO C/L* & $\operatorname{Massa}^{*}(\mathrm{~g})$ \\
\hline 1 & $9,6(14,8)$ & $9,1(14,4)$ & $0,9(4,6)$ & $7,1(12,7)$ \\
\hline 2 & $16,7(19,5)$ & $37,2(29,2)$ & $1,5(5,8)$ & $8,1(13,6)$ \\
\hline 3 & $25,1(24,0)$ & $57,7(36,3)$ & $1,5(6,0)$ & $12,8(17,1)$ \\
\hline 4 & $15,1(18,6)$ & $35,4(28,5)$ & $1,6(6,0)$ & $4,6(10,2)$ \\
\hline 5 & $63,5(38,1)$ & $39,2(30,0)$ & $1,7(6,2)$ & $10,9(15,8)$ \\
\hline
\end{tabular}

"Valores entre parênteses representam o Coeficiente de Variação (\%) das medidas

Tabela 3 - Tamanho mínimo de amostras representativo de uma população infinita do maracujá-amarelo, considerando 5\% de probabilidade e desvio de $10 \%$ em torno da média das medidas de caracterização física dos frutos no momento da colheita, contemplando sete estádios de maturação (EM). Os parâmetros de cor são relativos às faces expostas (FE) e não expostas (FNE) dos frutos

\begin{tabular}{lccccccccc}
\hline EM & $\begin{array}{c}\text { Hunter L } \\
(\mathbf{F E})^{*}\end{array}$ & $\begin{array}{c}\text { Hunter a } \\
(\mathbf{F E})^{*}\end{array}$ & $\begin{array}{c}\text { Hunter b } \\
(\mathbf{F E})^{*}\end{array}$ & $\begin{array}{c}\text { Hunter L } \\
(\mathbf{F N E})^{*}\end{array}$ & $\begin{array}{c}\text { Hunter a } \\
(\mathbf{F N E})^{*}\end{array}$ & $\begin{array}{c}\text { Hunter b } \\
(\mathbf{F N E})^{*}\end{array}$ & $\begin{array}{c}\text { EC* } \\
\text { C/L* }\end{array}$ & $\begin{array}{c}\text { Razão } \\
(\mathbf{m m})\end{array}$ & $\begin{array}{c}\text { RS* } \\
(\%)\end{array}$ \\
\hline 1 & $1,6(6,0)$ & $3,4(8,9)$ & $5,1(10,8)$ & $2,5(7,6)$ & $6,2(11,9)$ & $15,3(18,7)$ & $1,6(6,1)$ & $9,5(14,8)$ & $24,9(23,8)$ \\
2 & $4,3(10,0)$ & $4,7(10,4)$ & $23,0(23,0)$ & $7,1(12,7)$ & $6,9(12,6)$ & $26,9(24,8)$ & $2,2(7,1)$ & $22,9(22,9)$ & $31,5(26,7)$ \\
3 & $3,3(8,7)$ & $5,5(11,2)$ & $10,5(15,5)$ & $3,1(8,4)$ & $4,9(10,6)$ & $10,6(15,6)$ & $1,9(6,5)$ & $87,2(44,7)$ & $8,7(13,8)$ \\
4 & $4,6(10,2)$ & $13,1(17,2)$ & $10,4(15,3)$ & $4,7(10,3)$ & $19,7(21,1)$ & $7,7(13,2)$ & $2,1(7,0)$ & $8,2(13,6)$ & $6,9(12,5)$ \\
5 & $4,5(10,1)$ & $43,4(31,5)$ & $9,6(14,8)$ & $4,2(9,8)$ & $50,1(33,9)$ & $7,4(13,8)$ & $6,2(12,0)$ & $30,8(26,6)$ & $18,3(20,5)$ \\
6 & $2,8(8,1)$ & $37,6(29,3)$ & $8,4(13,8)$ & $1,6(6,0)$ & $136,3(55,9)$ & $3,8(9,4)$ & $2,9(8,1)$ & $9,1(14,4)$ & $5,2(10,9)$ \\
7 & $2,1(6,9)$ & $22,7(22,8)$ & $1,4(5,7)$ & $0,6(3,6)$ & $19,0(20,8)$ & $0,4(3,1)$ & $1,4(5,7)$ & $37,2(29,2)$ & $16,7(19,5)$ \\
\hline
\end{tabular}

*Valores entre parênteses representam o Coeficiente de Variação (\%) das medidas.

Rev. Ceres, Viçosa, v. 58, n.1, p. 23-28, jan/fev, 2011 
sólidos solúveis totais, açúcares redutores e açúcares solúveis totais, conforme observado nas Tabelas 5 e 6 , para os frutos analisados no momento da colheita e no final da estocagem, respectivamente. Verifica-se, contudo, que nos dois primeiros estádios de maturação ocorreram grandes valores de coeficiente de variação das medidas, atribuídos ao ponto de colheita imaturo dos frutos, que influenciou na variabilidade das medidas químicas do suco no momento da colheita e após o amadurecimento em condições de armazenamento.
Lorentz et al.(2004), estudando a cultura do pepineiro, cultivado em estufa, observaram que, em todas as colheitas, o valor do coeficiente de variação foi acima de $30 \%$, que deve ser classificado como alto, caracterizando grande variabilidade dos dados. Tavares et al.(2003) trabalharam com uma amostragem de três repetições, utilizando cinco frutos de maracujás-amarelos, por repetição, para avaliar as variáveis de sólidos solúveis totais, vitamina $\mathrm{C}$, acidez titulável, $\mathrm{pH}$ e perda de massa da matéria fresca. Verifica-se que, embora o trabalho tenha sido con-

Tabela 4 - Tamanho mínimo de amostras representativo de uma população infinita do maracujá-amarelo, considerando 5\% de probabilidade e desvio de $10 \%$ em torno da média das medidas de caracterização física dos frutos no final da estocagem, contemplando seis estádios de maturação (EM). Os parâmetros de cor são relativos às faces expostas (FE) e não expostas (FNE) dos frutos

\begin{tabular}{lcccccccccc}
\hline \multicolumn{10}{c}{ Tamanho mínimo de amostras (no de frutos) } \\
\hline EM & $\begin{array}{c}\text { Hunter L } \\
(\mathbf{F E})^{*}\end{array}$ & $\begin{array}{c}\text { Hunter a } \\
(\mathbf{F E})^{*}\end{array}$ & $\begin{array}{c}\text { Hunter b } \\
(\mathbf{F E})^{*}\end{array}$ & $\begin{array}{c}\text { Hunter L } \\
(\mathbf{F N E})^{*}\end{array}$ & $\begin{array}{c}\text { Hunter a } \\
(\mathbf{F N E})^{*}\end{array}$ & $\begin{array}{c}\text { Hunter b } \\
(\mathbf{F N E})^{*}\end{array}$ & $\begin{array}{c}\text { PM } \\
(\boldsymbol{\%})\end{array}$ & $\begin{array}{c}\text { RS* } \\
(\boldsymbol{\%})\end{array}$ & $\begin{array}{c}\text { EC* } \\
(\mathbf{m m})\end{array}$ & $\begin{array}{c}\text { Razão } \\
\text { C/L* }\end{array}$ \\
\hline 1 & $1,5(5,8)$ & $25,9(24,4)$ & $3,7(9,2)$ & $2,3(7,2)$ & $56,2(35,9)$ & $3,6(9,1)$ & $69,2(39,8)$ & $38,3(29,6)$ & $48,1(33,0)$ & $1,0(4,9)$ \\
2 & $0,7(3,9$ & $36,2(28,8)$ & $0,7(3,9)$ & $0,7(4,0)$ & $24,6(23,7)$ & $1,4(5,6)$ & $44,3(31,8)$ & $42,7(31,3)$ & $38,7(29,6)$ & $1,6(6,0)$ \\
3 & $0,4(3,0)$ & $30,5(26,4)$ & $1,6(6,0)$ & $0,3(2,4)$ & $35,5(28,5)$ & $2,7(7,9)$ & $20,6(21,7)$ & $5,7(11,5)$ & $20,7(21,3)$ & $1,2(5,3)$ \\
4 & $0,9(4,6)$ & $27,1(24,8)$ & $1,1(5,0)$ & $0,2(2,3)$ & $13,6(17,6)$ & $0,7(4,0)$ & $7,0(12,6)$ & $7,5(13,0)$ & $14,8(18,3)$ & $1,2(5,3)$ \\
5 & $0,5(3,3)$ & $15,1(18,6)$ & $1,4(5,7)$ & $0,5(3,3)$ & $18,8(20,7)$ & $0,7(4,0)$ & $31,5(26,8)$ & $19,2(21,0)$ & $17,1(19,8)$ & $2,1(7,0)$ \\
6 & $0,5(3,4)$ & $53,8(35,1)$ & $0,9(4,5)$ & $0,4(3,0)$ & $49,6(33,7)$ & $0,7(3,9)$ & $52,1(34,5)$ & $9,6(14,8)$ & $12,5(16,9)$ & $0,9(4,6)$ \\
\hline
\end{tabular}

Tabela 5 - Tamanho mínimo de amostras representativo de uma população infinita do maracujá-amarelo, considerando 5\% de probabilidade e desvio de $10 \%$ em torno da média das medidas de caracterização química dos frutos no momento da colheita, contemplando sete estádios de maturação (EM)

\begin{tabular}{|c|c|c|c|c|c|c|c|}
\hline \multicolumn{8}{|c|}{ Tamanho mínimo de amostras (no de frutos) } \\
\hline EM & $\begin{array}{c}\text { Vit. } C^{*} \\
(\mathrm{mg} / 100 \mathrm{~mL})\end{array}$ & $\begin{array}{c}\text { Acidez }^{*} \\
(\%)\end{array}$ & $\mathbf{p H}^{*}$ & $\begin{array}{c}\text { SST }^{*} \\
\left({ }^{\circ} \text { Brix }\right)\end{array}$ & $\begin{array}{c}\mathbf{A R}^{*} \\
(\mathrm{~g} / \mathbf{1 0 0 m L})\end{array}$ & $\begin{array}{c}\mathrm{AST}^{*} \\
(\mathrm{~g} / 100 \mathrm{~mL})\end{array}$ & $\begin{array}{c}\mathrm{AN \tilde {N }} \mathbf{R}^{*} \\
(\mathrm{~g} / \mathbf{1 0 0 m L})\end{array}$ \\
\hline 1 & $19,3(21,0)$ & $10,7(15,6)$ & $0,9(4,5)$ & $21,4(22,0)$ & $85,2(44,0)$ & $75,5(41,4)$ & $117,5(51,6)$ \\
\hline 2 & $25,4(24,0)$ & $17,8(20,1)$ & $1,5(5,8)$ & $29,8(26,0)$ & $345,5(88,5)$ & $54,0(35,0)$ & $120,5(52,3)$ \\
\hline 3 & $18,3(20,1)$ & $4,5(10,0)$ & $0,1(1,2)$ & $5,4(10,9)$ & $22,1(22,1)$ & $1,5(5,8)$ & $89,0(44,3)$ \\
\hline 4 & $14,1(17,9)$ & $5,3(11,0)$ & $0,1(1,5)$ & $4,0(9,5)$ & $9,7(14,9)$ & $1,3(5,3)$ & $16,1(18,2)$ \\
\hline 5 & $12,3(16,8)$ & $6,7(12,4)$ & $0,1(1,7)$ & $4,3(9,9)$ & $9,8(15,0)$ & $1,1(5,0)$ & $18,2(20,4)$ \\
\hline 6 & $13,5(17,6)$ & $2,2(7,0)$ & $0,1(1,0)$ & $1,5(5,9)$ & $4,7(10,4)$ & $0,5(3,4)$ & $5,5(11,2)$ \\
\hline 7 & $7,0(12,6)$ & $6,2(11,9)$ & $0,3(2,5)$ & $6,0(11,7)$ & $13,0(17,2)$ & $1,1(4,9)$ & $10,9(15,8)$ \\
\hline
\end{tabular}

"Valores entre parênteses representam o Coeficiente de Variação (\%) das medidas

Tabela 6 - Tamanho mínimo de amostras representativo de uma população infinita do maracujá-amarelo, considerando 5\% de probabilidade e desvio de $10 \%$ em torno da média das medidas de caracterização química dos frutos no final da estocagem, contemplando seis estádios de maturação (EM)

\begin{tabular}{lccccccc}
\hline \multicolumn{7}{c}{ Tamanho mínimo de amostras (no de frutos) } \\
\hline $\mathbf{E M}$ & $\begin{array}{c}\text { Vit. C } \\
(\mathbf{m g} / \mathbf{1 0 0 m L})\end{array}$ & $\begin{array}{c}\text { Acidez }^{*} \\
(\mathbf{\%})\end{array}$ & $\mathbf{p H}^{*}$ & $\begin{array}{c}\mathbf{S S T}^{*} \\
\left({ }^{\mathbf{o}} \mathbf{B r i x}\right)\end{array}$ & $\begin{array}{c}\mathbf{A R}^{*} \\
(\mathbf{g} / \mathbf{1 0 0 m L})\end{array}$ & $\begin{array}{c}\mathbf{A S T}^{*} \\
(\mathbf{g} / \mathbf{1 0 0 m L})\end{array}$ & $\begin{array}{c}\mathbf{A N}^{*} \mathbf{N R}^{*} \\
(\mathbf{g} / \mathbf{1 0 0 m L})\end{array}$ \\
\hline 1 & $24,9(23,9)$ & $26,1(24,4)$ & $1,0(4,7)$ & $54,4(35,3)$ & $195,2(66,9)$ & $145,1(57,6)$ & $1137,5(161,4)$ \\
2 & $21,6(22,3)$ & $12,7(17,0)$ & $0,2(2,4)$ & $24,5(23,7)$ & $52,7(34,7)$ & $54,8(34,1)$ & $163,9(61,3)$ \\
3 & $19,5(21,1)$ & $8,1(13,6)$ & $0,1(1,5)$ & $2,5(7,5)$ & $9,3(14,6)$ & $1,9(6,7)$ & $64,5(38,4)$ \\
4 & $12,7(17,0)$ & $3,0(8,3)$ & $0,1(1,2)$ & $3,8(9,3)$ & $21,7(22,2)$ & $1,1(5,0)$ & $31,6(26,8)$ \\
5 & $13,6(17,6)$ & $8,2(13,7)$ & $0,1(1,8)$ & $3,1(8,4)$ & $9,5(14,7)$ & $1,1(5,0)$ & $20,5(21,7)$ \\
6 & $17,9(20,2)$ & $7,9(13,4)$ & $0,2(1,9)$ & $2,1(7,0)$ & $5,0(10,7)$ & $0,5(3,4)$ & $24,4(23,7)$ \\
\hline
\end{tabular}

* Valores entre parênteses representam o Coeficiente de Variação (\%) das medidas 
duzido com repetições de amostras compostas de cinco frutos, as análises químicas foram feitas com uma amostragem compatível com amostras de uma população infinita identificadas no presente experimento. No entanto, na amostragem para análise de perda de massa seriam necessárias medidas de 52 frutos maduros.

Uma amostragem mais adequada foi utilizada por Farias et al.(2005), que avaliaram as características de comprimento longitudinal, diâmetro equatorial, espessura da casca, volume de suco, rendimento do suco, peso do fruto, sólidos solúveis totais, acidez total titulável, utilizando dez frutos por parcelas, com oito repetições.

\section{CONCLUSÕES}

Para os frutos colhidos maduros, com mais de $30 \%$ da área da casca amarelada, as amostras de 20 maracujásamarelos foram representativas de uma população infinita, considerando $95 \%$ de probabilidade e desvio de $10 \%$ em torno da média amostral, quando empregadas para a avaliação de acidez titulável (AT), pH, vitamina C, sólidos solúveis totais (SST), açúcares redutores (AR) e açúcares solúveis totais (AST).

Para os frutos colhidos imaturos os valores dos coeficientes de variação das medidas dos atributos de qualidade foram elevados e os tamanhos de amostras foram superiores a 20 frutos.

Na caracterização de tamanho dos maracujás, amostras de 20 frutos são representativas de uma população infinita quando empregadas para as análises de massa dos frutos, razão comprimento/largura (Razão C/L) e rendimento em suco (RS).

Para a avaliação de espessura da casca (EC) são necessárias amostras de 58 frutos.

$\mathrm{Na}$ caracterização física dos frutos em diferentes estádios de maturação, as amostras de 20 frutos são representativas de população infinita quando empregadas para avaliação da cor pelos parâmetros de Hunter $L$ e $b$ e Razão C/L.

Medidas de RS e EC necessitaram de amostras com mais de 20 frutos, nos estádios imaturos.

Avaliações de perda de massa (PM) e parâmetro de Hunter $a$ apresentaram grande coeficiente de variação, necessitando de amostras com 69 e 136 frutos, respectivamente.

\section{AGRADECIMENTOS}

À FAPERJ, pelo apoio financeiro, ao CNPq, pelos recursos financiados ao projeto CTAGRO/Edital MCT/ CNPq n ${ }^{\circ}$ 04/2006 - Arranjos Produtivos Locais em Fruticultura, ao Sr. Jaime Viana, pela matéria-prima utilizada neste trabalho.

\section{REFERÊNCIAS}

AOAC (1970) Methods of Analysis of the Association of Official Analytical Chemists, Washington, 1015p.

Cunha MAP, Barbosa LV \& Junqueira NTV (2002) Espécies de maracujazeiro. Maracujá produção: aspectos técnicos. Brasília, Embrapa Informações Tecnológicas, Frutas do Brasil, 15:104.

Farias MAA, Faria GA, Cunha MAP, Peixoto CP \& Sousa, JS (2005) Caracterização física e química de frutos de maracujá amarelo de ciclo de seleção massa estratificada e de populações regionais. Magistra, 17:83-87.

Freitas JA (2001) Tamanho de amostra para caracterização de algodoeiro herbáceo. Ciência Rural, 31:583-587.

IBGE Instituto Brasileiro de Geografia e Estatística (2006) Dados de agricultura. Disponível em <http://www.sidra.ibge.gov.br/bda/ agric/default.asp? $\mathrm{z}=\mathrm{t} \& \mathrm{o}=10 \& \mathrm{i}=\mathrm{P}>$ Acessado em: 03 de Fevereiro de 2008 .

Lorentz LH, Lúcio ADC, Storck L, Lopes SJ, Boligon AA \& Carpes RH (2004) Variação temporal do tamanho de amostra para experimentos em estufa plástica. Ciência Rural, 34:1043-1049.

Miranda JF (2004) Reação de variedades de maracujazeiro amarelo a bacteriose causada por xanthomonas campestris $p v$. Passiflorae. Dissertação de Mestrado. Piracicaba-SP, Escola superior de agricultura "Luis de Queiroz". 62p.

Nascimento TB, Ramos JD \& Menezes JB (1999) Características físicas do maracujá amarelo produzido em diferentes épocas. Pesquisa Agropecuária Brasileira, 34:2353-2358

Nunes GHS, Torquato JE, Júnior RS, Ferreira HA \& Neto FB (2006) Tamanho amostral para estimar o teor de sólidos solúveis totais em talhões de melão amarelo. Revista Caatinga, 19:117-122.

Ramalho MAP, Ferreira DF \& Oliveira AC (2000) Experimentação em genética e melhoramento de plantas. Lavras, UFLA, $326 \mathrm{p}$.

SAEG (2007) Sistema para Análises Estatísticas, Versão 9.1: Fundação Arthur Bernardes, UFV, Viçosa, 2007

Sândi D, Chaves JBP, Souza ACG, Silva MTC \& Parreiras JFM (2003) Correlações entre características físico-químicas e sensoriais em suco de maracujá-amarelo (Passiflora edulis var. flavicarpa) durante o armazenamento. Ciência e Tecnologia de Alimentos, 23:355-361.

Steel RGD, Torrie JH \& Dickey DA (1997) Principles and procedures of statistics: a biometrical approach, New York, Mc Graw-Hill., 666p.

Storck L \& Lopes SJ (1997) Experimentação II. Santa Maria, UFSM, 197p.

Tavares JTQ, Silva CL, Carvalho LA, Silva MA, Santos CMG, Teixeira LJ \& Santana RS (2003) Aplicação pós-colheita de cloreto de cálcio em maracujá amarelo. Magistra, 15: jan/jun.

Vianna-Silva T, Resende ED, Viana AP, Pereira SMF, Carlos LA \& Vitorazi L (2008) Qualidade do suco de maracujá-amarelo em diferentes épocas de colheita. Ciência e Tecnologia de Alimentos, 28:545-550. 